\title{
Statistical Approach for Production of PUFA from Kocuria sp. BRI 35 Isolated from Marine Water Sample
}

\author{
Swanandi Pote and Rama Bhadekar \\ Department of Microbial Biotechnology, Rajiv Gandhi Institute of I.T. and Biotechnology, Bharati Vidyapeeth Deemed University, \\ Katraj, Pune, Maharashtra 411046, India
}

Correspondence should be addressed to Rama Bhadekar; neeta.bhadekar@gmail.com

Received 6 February 2014; Revised 5 April 2014; Accepted 9 April 2014; Published 25 May 2014

Academic Editor: Frederick D. Quinn

Copyright (C) 2014 S. Pote and R. Bhadekar. This is an open access article distributed under the Creative Commons Attribution License, which permits unrestricted use, distribution, and reproduction in any medium, provided the original work is properly cited.

In this study, Plackett-Burman design was used to identify the most influential parameters affecting PUFA production by Kocuria sp. BRI 35 isolated from Antarctic water sample. Amongst 10 variables evaluated, magnesium chloride, protease peptone, glucose, and temperature were significant. Response surface methodology consisting of a central composite design was developed to study the interactions between the variables and to determine optimal values of significant variables. A quadratic model $(R=0.9652, F=14.64$, $P<0.0001)$ was built. The contour plots indicated that the isolate produced maximum PUFA at lower concentrations of magnesium sulfate $(0.9 \mathrm{~g} / \mathrm{L})$ and higher concentrations of protease peptone $(5 \mathrm{~g} / \mathrm{L})$ and glucose $(10 \mathrm{~g} / \mathrm{L})$ at $15^{\circ} \mathrm{C} . \mathrm{MgSO}_{4}$ and glucose exhibited quadratic as well as interactive effect on PUFA production whereas protease peptone and temperature showed interactive effects only. After optimization, PUFA production per unit biomass increased from $0.94 \mathrm{mg} / \mathrm{g}$ to $11.12 \mathrm{mg} / \mathrm{g}$. This represented an increase from $3 \%$ to $58.62 \%$ of the total fatty acids. Among PUFAs, the yield of $\omega-6$ fatty acids increased from $9.66 \mathrm{mg} / \mathrm{L}$ to $107.71 \mathrm{mg} / \mathrm{L}$ with significant increase in linoleic acid $(20.36 \mathrm{mg} / \mathrm{L})$ whereas $\omega-3$ fatty acids increased up to $12.37 \mathrm{mg} / \mathrm{L}$ with DHA being the major $\omega-3$ fatty acid produced.

\section{Introduction}

Research on production and purification of polyunsaturated fatty acids (PUFAs) has gained a lot of significance due to their role in human health and nutrition. PUFAs are fatty acids that have more than one double bond in their back bone structure. Based on the position of their double bonds they are grouped as $\omega-3, \omega-6$, and $\omega-9$ fatty acids. Amongst these $\omega$-3 fatty acids (alpha linolenic acid (ALA), eicosapentaenoic acid (EPA), and docosahexaenoic acid (DHA)) and $\omega-6$ fatty acids (linoleic acid (LA), gamma linolenic acid (GLA), and arachidonic acid (AA)) are of importance in human health [1]. Moreover humans lack the enzymes required for synthesis of these acids [2]. Hence the only way to obtain these fatty acids is through nutrition. Deficiencies of $\omega-3$ and $\omega-6$ fatty acids are known to adversely affect the development and proper functioning of brain and central nervous system. Lack of these acids may lead to neurological disorders like attention deficit hyperactivity disorder (ADHD), dyslexia, dyspraxia, and autism [3]. Apart from neurological disorders PUFA deficiency has also been linked to various cardiovascular, cerebrovascular, autoimmune diseases and cancers [4]. $\omega-3$ fatty acids are also known for their anti-inflammatory properties [5]. Widespread awareness about the benefit of PUFAs has led to increase in commercial production of PUFAs.

Fish oil is the most widely used source for obtaining PUFAs. However, this oil gets easily oxidized and hence is often associated with unpleasant taste and odor [6]. Besides, decrease in fish population and contamination of marine ecosystems with chemicals, heavy metals, and so forth are other factors that hamper the use of fish oil for PUFA production. Even though vegetable oils like corn oil, soybean oil, palm oil, and so forth provide an alternative source for PUFAs, they are often a complex mixture of various fatty acids [7]. Hence, extensive purification procedures become a necessity if these oils are to be used for obtaining PUFAs [8]. As a result, cost of PUFA production is greatly increased. 
In order to alleviate these problems other sources of PUFAs are now being explored. In light of this, microorganisms prove to be very promising alternative source. The superiority of microbes lies in the fact that they produce single PUFA in high quantities with high oxidative stability leading to reduced production and purification cost. Moreover, microorganisms are renewable source for PUFAs [9]. Thus, microbes not only surpass the disadvantages of other sources but also offer a quick and economical alternative for obtaining PUFAs.

Several fungi and bacteria are known to produce commercially important PUFAs. EPA production has been reported from Moritella (25 mg/g) [10] and Pythium (90 mg/L) [11], whereas Thraustochytrium [12] produces DHA (23 mg/L). Among $\omega-6$ fatty acids, Klempova et al. [13] have reported GLA production $(217 \mathrm{mg} / \mathrm{L})$ from Umbelopsis isabellina CCF 2412. On the other hand Mortierella alpina produces AA (40-43\% of total fatty acids) [14]. Bacteria especially from cold regions like Antarctica produce high amounts of PUFAs as an adaptation to the habitat [1]. However the arena of bacterial PUFAs is relatively new. To name a few, Shewanella species $(10.3 \%$ of total fatty acids) [15], Aureispira sp. (21.5 mg/L of AA) [16], and Photobacterium sp. [17] are the examples of PUFA producing bacteria. Nichols et al. [18] have reviewed PUFA producing bacteria from the Antarctic region.

Considering importance of PUFA in human health and suitability of microbial sources, many researchers have published work on optimization of PUFA production from microorganisms $[10,19,20]$. Traditionally, a method of varying one parameter at a time has been employed for this. However, the method is time consuming and costly. The method does not evaluate the effect of interaction between variables and the influence of more than one variable simultaneously. Therefore, other statistical methods that allow such studies are preferred. The most commonly used statistical method for optimization of various parameters under study is response surface methodology (RSM). Use of RSM has great advantage since (i) significant variables can be easily identified, (ii) large amount of information about the system under study is obtained, (iii) it requires relatively few number of experiments, (iv) it allows interactive study of variables, (v) it is computationally less demanding, (vi) it predicts repose for conditions other than those under study, (vii) and it is less time consuming and economical [21]. So far several reports that highlight the use of RSM for optimization of PUFA production are available. Studies reporting use of RSM have been published by Zhou et al. [19] for DHA production from Schizochytrium sp., Elrazak et al. [20] for EPA production from marine bacteria, and so forth.

In this paper we report optimization of PUFA production from Kocuria sp. BRI 35. The most significant variables were identified using Plackett-Burman design. These variables were further optimized using RSM. To our knowledge this is the first report on optimization studies for PUFA production from Kocuria species.
TABLE 1: Variables studied using Plackett-Burman design.

\begin{tabular}{|c|c|c|c|}
\hline Variable & Code & $\begin{array}{l}\text { High value } \\
\qquad(+1)\end{array}$ & $\begin{array}{l}\text { Low value } \\
\quad(-1)\end{array}$ \\
\hline $\mathrm{NaCl}(\mathrm{g} / \mathrm{L})$ & Y1 & 80 & 40 \\
\hline Yeast extract (YE) (g/L) & Y2 & 10 & 1 \\
\hline $\mathrm{MgSO}_{4}(\mathrm{~g} / \mathrm{L})$ & Y3 & 9.6 & 0.9 \\
\hline $\mathrm{MgCl}_{2}(\mathrm{~g} / \mathrm{L})$ & Y4 & 7 & 0.7 \\
\hline Protease peptone (P.Pep.) (g/L) & Y5 & 5 & 0.5 \\
\hline $\mathrm{KCl}(\mathrm{g} / \mathrm{L})$ & Y6 & 2 & 0.2 \\
\hline Glucose $(\mathrm{g} / \mathrm{L})$ & Y7 & 10 & 1 \\
\hline $\mathrm{CaCl}_{2}(\mathrm{~g} / \mathrm{L})$ & Y8 & 0.3 & 0.03 \\
\hline Temperature $\left({ }^{\circ} \mathrm{C}\right)$ & Y9 & 25 & 15 \\
\hline $\mathrm{pH}$ & Y10 & 8.5 & 6.5 \\
\hline
\end{tabular}

\section{Materials and Methods}

2.1. Chemicals. All the media components and chemicals were purchased from Sigma Aldrich, Hi Media, and Merck (Mumbai, India) and were of analytical grade.

2.2. Organism. BRI 35 was isolated from marine water sample (latitude $\mathrm{S} 51^{\circ} 06^{\prime} 34.4^{\prime \prime}$ and longitude E $57^{\circ} 35^{\prime} 40.2^{\prime \prime}$ ). The isolate was maintained on marine salt medium (MSM) (composition per litre: $81.0 \mathrm{~g} \mathrm{NaCl}, 10.0 \mathrm{~g}$ yeast extract, $9.6 \mathrm{~g}$ $\mathrm{MgSO}_{4}, 7.0 \mathrm{~g} \mathrm{MgCl}_{2}, 5.0 \mathrm{~g}$ protease peptone, $2.0 \mathrm{~g} \mathrm{KCl}, 1.0 \mathrm{~g}$ glucose, $0.36 \mathrm{~g} \mathrm{CaCl}_{2}, 0.06 \mathrm{~g} \mathrm{NaHCO}_{3}, 0.026 \mathrm{~g} \mathrm{NaBr}$, and $15 \mathrm{~g}$ agar with $\mathrm{pH}$ adjusted to $7.0 \pm 0.2$ ). BRI 35 was identified using $16 \mathrm{~S}$ rRNA gene sequencing.

The organism was grown in MSM at $25^{\circ} \mathrm{C}$ and $120 \mathrm{rpm}$ for 48 hours (h) and was further used for inoculation in all the experiments at $10 \%$ concentration. For measurement of microbial biomass $(\mathrm{g} / \mathrm{L})$ the cell pellets were lyophilized. For determination of lipid content, lipids in the cells were extracted, dried, and weighed according to method described by Bligh and Dyer [22]. Estimation of lipids was carried out using phosphovanillin reagent [23].

\subsection{Analysis of PUFA Production}

2.3.1. Preparation of FAMEs. For all the experiments cell mass was obtained by centrifugation at 10,000 rpm for 10 minutes. $1 \mathrm{~g}$ of cell mass was boiled for $20 \mathrm{~min}$ in $0.5 \mathrm{~N}$ methanolic sodium hydroxide solution. Further $5 \mathrm{~mL}$ of boron trifluoride (methanolic) was added to the mixture. This was followed by vortexing and 15 minutes of incubation. The FAMEs thus prepared were extracted in $1 \mathrm{~mL}$ heptane [24].

2.3.2. GC-FID for FAMEs. A gas chromatograph equipped with a $60 \mathrm{~m} \times 250 \mu \mathrm{m} \times 0.25 \mu \mathrm{m}$ gas capillary column and a flame ionization detector was employed for FAMEs analyses. Nitrogen was used as a carrier gas at a pressure of 19.865 psi. $1 \mu \mathrm{L}$ of sample was injected using split mode. Initial temperature of the column was $110^{\circ} \mathrm{C}$ which was increased up to $250^{\circ} \mathrm{C}$ at a rate of $3^{\circ} \mathrm{C}$ per minute. The column was maintained at $250^{\circ} \mathrm{C}$ for 2 minutes. The fatty acids present 
TABLE 2: Plackett-Burman design for evaluating the significant variables for PUFA production by Kocuria sp. BRI 35.

\begin{tabular}{|c|c|c|c|c|c|c|c|c|c|c|c|c|}
\hline Run & $\mathrm{Y} 1$ & $\mathrm{Y} 2$ & Y3 & Y4 & Y5 & Y6 & Y7 & Y8 & Y9 & Y10 & Dummy & $\begin{array}{c}\text { PUFA production } \\
(\% \text { of total fatty acids) } \\
{[\text { mean } \pm \text { standard error }]}\end{array}$ \\
\hline 1 & -1 & -1 & -1 & -1 & -1 & -1 & -1 & -1 & -1 & -1 & -1 & $20.5 \pm 0.56$ \\
\hline 2 & +1 & +1 & -1 & -1 & -1 & +1 & -1 & +1 & +1 & -1 & +1 & $1.0 \pm 0.16$ \\
\hline 3 & +1 & +1 & -1 & +1 & +1 & +1 & -1 & -1 & -1 & +1 & -1 & $1.69 \pm 0.08$ \\
\hline 4 & +1 & -1 & +1 & +1 & +1 & -1 & -1 & -1 & +1 & -1 & +1 & $0.95 \pm 0.20$ \\
\hline 5 & -1 & +1 & +1 & +1 & -1 & -1 & -1 & +1 & -1 & +1 & +1 & $13.29 \pm 0.62$ \\
\hline 6 & 0 & 0 & 0 & 0 & 0 & 0 & 0 & 0 & 0 & 0 & 0 & $3.0 \pm 0.06$ \\
\hline 7 & -1 & +1 & -1 & +1 & +1 & -1 & +1 & +1 & +1 & -1 & -1 & $1.36 \pm 0.41$ \\
\hline 8 & +1 & -1 & +1 & +1 & -1 & +1 & +1 & +1 & -1 & -1 & -1 & $22.37 \pm 0.61$ \\
\hline 9 & -1 & +1 & +1 & -1 & +1 & +1 & +1 & -1 & -1 & -1 & +1 & $2.51 \pm 0.59$ \\
\hline 10 & -1 & -1 & -1 & +1 & -1 & +1 & +1 & -1 & +1 & +1 & +1 & $2.57 \pm 0.26$ \\
\hline 11 & +1 & -1 & -1 & -1 & +1 & -1 & +1 & +1 & -1 & +1 & +1 & $7.94 \pm 0.68$ \\
\hline 12 & -1 & -1 & +1 & -1 & +1 & +1 & -1 & +1 & +1 & +1 & -1 & $1.83 \pm 0.50$ \\
\hline 13 & +1 & +1 & +1 & -1 & -1 & -1 & +1 & -1 & +1 & +1 & -1 & $3.25 \pm 0.47$ \\
\hline
\end{tabular}

TABle 3: Statistical analysis of Plackett-Burman design.

\begin{tabular}{lcc}
\hline Variables & Coefficient & $P$ value \\
\hline $\mathrm{NaCl}$ & 1.13 & 0.1413 \\
Yeast extract & -1.22 & 0.1256 \\
$\mathrm{MgSO}_{4}$ & 2.30 & $\mathbf{0 . 0 4 0 6}$ \\
$\mathrm{MgCl}_{2}$ & 1.97 & 0.0541 \\
Protease peptone & -2.35 & $\mathbf{0 . 0 3 8 8}$ \\
$\mathrm{KCl}$ & 0.26 & 0.6399 \\
$\mathrm{CaCl}_{2}$ & 1.60 & 0.0789 \\
$\mathrm{Glucose}$ & 2.90 & $\mathbf{0 . 0 2 6 1}$ \\
$\mathrm{Temperature}$ & -3.24 & $\mathbf{0 . 0 2 1 1}$ \\
$\mathrm{pH}$ & 0.028 & 0.9593 \\
\hline
\end{tabular}

were detected by comparison of the retention time with those of standards.

2.3.3. Determination of Significant Variables for PUFA Production. The significant variables affecting PUFA production from Kocuria sp. BRI 35 were identified using the PlackettBurman design. In all, 8 nutritional factors, namely, sodium chloride $(\mathrm{NaCl})$, yeast extract $(\mathrm{YE})$, magnesium sulfate $\left(\mathrm{MgSO}_{4}\right)$, magnesium chloride $\left(\mathrm{MgCl}_{2}\right)$, protease peptone (P.Pep), potassium chloride $(\mathrm{KCl})$, glucose, and calcium chloride $\left(\mathrm{CaCl}_{2}\right)$, along with 2 physical parameters, namely, temperature and $\mathrm{pH}$, were evaluated. Each factor was studied at two levels. The variables studied and their high $(+1)$ and low levels $(-1)$ are presented in Table 1. A design for 12 experiments was generated using Design-Expert version 8.0 (Stat-Ease, Inc., Minneapolis, USA) software (Table 2). An additional experiment where the variables were maintained at values equal to those in MSM was included in the design along with the standard 12 experiments. The organism was cultivated in $100 \mathrm{~mL}$ medium in $250 \mathrm{~mL}$ Erlenmeyer flasks for 48 hours. All the experiments were carried out in triplicate and the response was measured in terms of the amount of PUFA produced by the organism. The variables with $P$ value $<0.05$ were considered to be significant.

2.3.4. Central Composite Design (CCD). The significant variables identified using the Plackett-Burman design were optimized using response surface methodology. A central composite design (CCD) matrix for 4 significant variables was generated. The total number of experiments generated was $2^{k}+2 K+n_{0}$ (where $k$ is the number of independent variables and $n_{0}$ is the number of experiments carried out at central point values of variables). The matrix consisted of 6 central points and included experiments where one variable was set at extreme \pm 2 level and the other variables were maintained at central point level. In experimental runs where the software generated negative values, that component was not added in the medium. Table 4 summarizes the coded levels of the variables and their actual values. Table 5 gives the design matrix and the response, that is, amount of PUFAs produced. The coding of the variables was done in accordance with the following equation:

$$
y_{c}=\frac{Y c-Y c p}{\Delta y c},
$$

where $y_{c}$ is coded level, $Y c$ is actual value, $Y c p$ is real value of central point, and $\Delta y c$ is the step change. The amount of PUFAs produced can be expressed by the quadratic equation

$$
X=\beta_{0}+\sum \beta_{c} y_{c}+\sum \beta_{c c} y_{c}^{2}+\sum \beta_{c b} y_{c} y_{b},
$$

where $X$ is predicted response; $\beta_{0}$ is the intercept; $\beta_{c}, \beta_{c c}$, and $\beta_{c b}$ are linear, quadratic, and interactive coefficients, respectively.

The responses generated were analyzed using DesignExpert version 8.0. They were subjected to multiple regression analysis for calculation of the coefficients. The significance of the model was determined for testing its efficiency. 
TABLE 4: Coded and real values of variables selected for CCD.

\begin{tabular}{|c|c|c|c|c|c|c|c|}
\hline \multirow{2}{*}{ Variable } & \multirow{2}{*}{ Symbol } & \multirow{2}{*}{ Unit } & \multicolumn{5}{|c|}{ Coded levels } \\
\hline & & & -2 & -1 & 0 & +1 & +2 \\
\hline $\mathrm{MgSO}_{4}$ & $A$ & $\mathrm{~g} / \mathrm{L}$ & -3.45 & 0.90 & 5.25 & 9.60 & 13.95 \\
\hline Protease Peptone & $B$ & $\mathrm{~g} / \mathrm{L}$ & -1.75 & 0.50 & 2.75 & 5.0 & 7.25 \\
\hline Glucose & C & $\mathrm{g} / \mathrm{L}$ & -3.50 & 1.00 & 5.50 & 10 & 14.50 \\
\hline Temperature & $D$ & ${ }^{\circ} \mathrm{C}$ & 10 & 15 & 20 & 25 & 30 \\
\hline
\end{tabular}

TABLE 5: CCD matrix of variables with response.

\begin{tabular}{|c|c|c|c|c|c|c|}
\hline \multirow[t]{2}{*}{ Run } & \multirow[t]{2}{*}{$\mathrm{MgSO}_{4}$} & \multirow[t]{2}{*}{ Protease peptone } & \multirow[t]{2}{*}{ Glucose } & \multirow[t]{2}{*}{ Temperature } & \multicolumn{2}{|c|}{$\begin{array}{c}\text { PUFA production } \\
\text { (\% of total fatty acids) } \\
\text { [Mean } \pm \text { standard error] }\end{array}$} \\
\hline & & & & & Actual values & Predicted values \\
\hline 1 & -1 & +1 & -1 & -1 & $57.86 \pm 0.92$ & 58.45 \\
\hline 2 & -1 & -1 & -1 & +1 & $10.11 \pm 0.96$ & 9.48 \\
\hline 3 & +1 & +1 & -1 & -1 & $38.13 \pm 1.19$ & 33.80 \\
\hline 4 & 0 & 0 & 0 & +2 & $11.78 \pm 0.79$ & 4.6 \\
\hline 5 & 0 & 0 & 0 & 0 & $17.26 \pm 0.34$ & 17.25 \\
\hline 6 & +1 & +1 & +1 & -1 & $6.53 \pm 0.46$ & 13.86 \\
\hline 7 & +1 & -1 & +1 & -1 & $18.57 \pm 0.60$ & 11.90 \\
\hline 8 & 0 & 0 & 0 & 0 & $16.78 \pm 0.85$ & 17.25 \\
\hline 9 & +1 & +1 & +1 & +1 & $2.32 \pm 0.30$ & 0.98 \\
\hline 10 & 0 & 0 & 0 & 0 & $19.6 \pm 0.52$ & 17.25 \\
\hline 11 & 0 & 0 & +2 & 0 & $44.81 \pm 0.86$ & 42.76 \\
\hline 12 & -1 & -1 & -1 & -1 & $9.97 \pm 0.09$ & 8.70 \\
\hline 13 & +1 & +1 & -1 & +1 & $7.96 \pm 0.05$ & 18.13 \\
\hline 14 & -1 & +1 & +1 & +1 & $11.42 \pm 0.29$ & 14.22 \\
\hline 15 & +2 & 0 & 0 & 0 & $29.81 \pm 0.41$ & 26.49 \\
\hline 16 & +1 & -1 & +1 & +1 & $42.66 \pm 0.86$ & 48.69 \\
\hline 17 & -2 & 0 & 0 & 0 & $31.25 \pm 0.19$ & 30.54 \\
\hline 18 & 0 & -2 & 0 & 0 & $14.52 \pm 0.20$ & 19.01 \\
\hline 19 & +1 & -1 & -1 & +1 & $56.26 \pm 0.45$ & 51.88 \\
\hline 20 & 0 & +2 & 0 & 0 & $29.57 \pm 0.55$ & 21.04 \\
\hline 21 & -1 & -1 & +1 & +1 & $26.37 \pm 0.68$ & 28.09 \\
\hline 22 & 0 & 0 & 0 & 0 & $16.29 \pm 0.24$ & 17.25 \\
\hline 23 & -1 & +1 & +1 & -1 & $58.62 \pm 0.35$ & 60.39 \\
\hline 24 & 0 & 0 & 0 & 0 & $18.35 \pm 0.51$ & 17.25 \\
\hline 25 & 0 & 0 & -2 & 0 & $45.99 \pm 0.49$ & 44.01 \\
\hline 26 & 0 & 0 & 0 & 0 & $15.28 \pm 0.42$ & 17.25 \\
\hline 27 & +1 & -1 & -1 & -1 & $14.07 \pm 0.08$ & 17.89 \\
\hline 28 & -1 & +1 & -1 & +1 & $5.42 \pm 0.52$ & 9.48 \\
\hline 29 & -1 & -1 & +1 & -1 & $28.15 \pm 1.70$ & 24.60 \\
\hline 30 & 0 & 0 & 0 & -2 & $13.65 \pm 0.28$ & 16.79 \\
\hline
\end{tabular}

The model under study was considered to be fit for optimization if it had a significant $F$ value and a good multiple correlation coefficient $(R)$. The fermentation conditions to obtain maximum PUFA production from BRI 35 were predicted using numerical optimization in the software. The factors under study were varied and the remaining variables were kept at level equal to those in MSM.

\section{Results and Discussion}

3.1. Organism. BRI 35 was maintained on MSM slants. The DNA was extracted using standard protocols and the isolate was identified using $16 \mathrm{~S}$ rRNA gene sequencing. The results indicated it belonged to the genus Kocuria (99\% similarity, 1288 bp) (GenBank accession number: KF366396) [25]. 
TABLE 6: ANNOVA for quadratic model.

\begin{tabular}{lcccc}
\hline Source & Sum of squares & $\mathrm{df}$ & $F$ value & $P$ value \\
\hline Model & 7151.88 & 14 & 14.64 & $<\mathbf{0 . 0 0 0 1}$ \\
$A$ & 24.60 & 1 & 0.71 & 0.4142 \\
$B$ & 6.20 & 1 & 0.18 & 0.6793 \\
$C$ & 2.34 & 1 & 0.067 & 0.7990 \\
$D$ & 222.77 & 1 & 6.39 & $\mathbf{0 . 0 2 3 2}$ \\
$A B$ & 1144.81 & 1 & 32.81 & $<\mathbf{0 . 0 0 0 1}$ \\
$A C$ & 478.95 & 1 & 13.73 & $\mathbf{0 . 0 0 2 1}$ \\
$A D$ & 1108.56 & 1 & 31.77 & $<\mathbf{0 . 0 0 0 1}$ \\
$B C$ & 194.74 & 1 & 5.58 & $\mathbf{0 . 0 3 2 1}$ \\
$B D$ & 2466.61 & 1 & 70.70 & $<\mathbf{0 . 0 0 0 1}$ \\
$C D$ & 7.81 & 1 & 0.22 & 0.6429 \\
$A^{2}$ & 217.32 & 1 & 6.23 & $\mathbf{0 . 0 2 4 7}$ \\
$B^{2}$ & 13.19 & 1 & 0.38 & 0.5478 \\
$C^{2}$ & 1170.40 & 1 & 33.55 & $<\mathbf{0 . 0 0 0 1}$ \\
$D^{2}$ & 73.68 & 1 & 2.11 & 0.1668 \\
\hline
\end{tabular}

3.2. Determination of Significant Variables for PUFA Production. Plackett-Burman design was used to identify the significant variables affecting PUFA production from Kocuria sp. BRI 35. Eight nutritional and two physical parameters were studied at high and low levels. Table 2 demonstrates the experimental design and the response generated in terms of the amount of PUFAs produced. The effect of each variable was determined by the following equation:

$$
X=\frac{2\left[\sum R^{+}-R^{-}\right]}{N},
$$

where $X$ is the effect of the tested variable, $R^{+}$and $R^{-}$are the responses for high and low values, respectively, and $N$ is the total number of experiments. The final equation generated in terms of actual factors was

$$
\begin{aligned}
R= & +4.90846+1.13250 * \mathrm{NaCl}-1.21750 * \mathrm{YE} \\
& +2.29917 * \mathrm{MgSO}_{4}+1.97083 * \mathrm{MgCl}_{2} \\
& -2.35417 * \mathrm{P} . \mathrm{Pep}+0.26083 * \mathrm{KCl} \\
& +1.59917 * \mathrm{CaCl}_{2}+2.89750 * \text { Glucose } \\
& -3.24083 * \text { Temperature }+0.027500 * \mathrm{pH} .
\end{aligned}
$$

The results thus obtained were subjected to statistical analysis using Design-Expert software. The variables were segregated on the basis of their $P$ value at the confidence level of 95\% ( $P$ value $<0.05)$ and those with $P$ value $<0.05$ were considered to be significant. Table 3 shows analysis of variance (ANNOVA) for PUFA production. Based on the results of ANNOVA, $\mathrm{MgSO}_{4}(P=0.0406)$, protease peptone $(P=0.0388)$, glucose $(P=0.0261)$, and temperature $(P=0.0211)$ were identified as variables that significantly affect PUFA production from Kocuria sp. BRI 35. On the other hand, variables like $\mathrm{NaCl}, \mathrm{YE}, \mathrm{MgCl}_{2}, \mathrm{CaCl}_{2}$, and $\mathrm{pH}$ exhibited $P$ values $>0.05$ and hence were considered to be insignificant for PUFA production. Literature review suggests that amount of PUFA produced by microorganisms is greatly influenced by the temperature at which the microorganism is cultivated. Generally, microorganisms tend to produce more amounts of PUFAs at lower temperatures $\left(5-25^{\circ} \mathrm{C}\right)[2,26,27]$. Along with temperature, the amount of carbon and nitrogen sources, that is, $\mathrm{C}: \mathrm{N}$ ratio [28], and the concentrations of salts like $\mathrm{MgSO}_{4}, \mathrm{CaCl}_{2}$, and so forth in the medium are also known to affect the type and amount of PUFAs produced [29]. Our observations are in-line with these findings. The significant parameters thus identified were selected for further optimization of PUFA production.

3.3. Central Composite Design. Response surface methodology was used to optimize the concentrations of the significant parameters identified by Plackett-Burman design. In order to evaluate the interactive effect of the variables, experiments involving different combinations of variables were designed. Accordingly, CCD matrix consisting of a factorial design with 6 replications of the central point was developed. Multiple regression analysis of the experimental data generated the following equation for PUFA production in terms of actual factors:

$$
\begin{aligned}
R 1= & -23.76481-5.53477 * \mathrm{MgSO}_{4}+27.97817 * \text { P.Pep } \\
& -1.82401 * \text { Glucose }+2.86810 * \text { Temperature } \\
& -0.86424 * \mathrm{MgSO}_{4} * \mathrm{P} . \mathrm{Pep}-0.27950 * \mathrm{MgSO}_{4} \\
& * \text { Glucose }+0.38270 * \mathrm{MgSO}_{4} * \text { Temperature } \\
& -0.34457 * \text { P.Pep } * \text { Glucose }-1.10367 * \text { P.Pep } \\
& * \text { Temperature }+0.031056 * \text { Glucose } * \text { Temperature } \\
& +0.14875 * \mathrm{MgSO}_{4}{ }^{2}+0.13700 * \text { P.Pep }^{2}+0.32258 \\
& * \text { Glucose }^{2}-0065558 * \text { Temperature }^{2} .
\end{aligned}
$$

The statistical significance of the quadratic model built was studied by F-test and analysis of variance (ANNOVA) (Table 6). The efficiency of the model was determined by studying its characteristics. The model was found to have $F$ value of 14.64 indicating that there is only $0.01 \%$ chance that such a high model $F$ value could occur due to noise. The $P$ value of the model was less than 0.0001 . This clearly identifies a reliability of $99.9 \%$. Multiple regression coefficient $R$ and coefficient $R^{2}$ of the model were also determined. The closer the value of $R$ to 1 , the better the correlation between experimental and predicted values $[30,31]$. In the case of this model, multiple regression coefficient $R$ had a value of 0.9652 illustrating a very good correlation between the experimental and predicted values (Table 5). The $R^{2}$ was 0.9318 whereas the value of adjusted $R^{2}$ was 0.9078 . This suggests that around $94 \%$ of variation is due to the independent variables and only $6 \%$ of the variation cannot be explained by the model. Also the standard deviation was 5.91 which is less than 10 . Hence, the model is highly significant and can be efficiently used for response prediction. 
TABLE 7: Increase in PUFA production after optimization.

\begin{tabular}{lcccc}
\hline Design & $\begin{array}{c}\text { \% PUFA produced } \\
\text { [mean } \pm \text { standard error }]\end{array}$ & PUFA produced $(\mathrm{mg} / \mathrm{L})$ & Dry cell weight $(\mathrm{g} / \mathrm{L})$ & $\begin{array}{c}\text { PUFA produced per } \\
\text { unit biomass }(\mathrm{mg} / \mathrm{g})\end{array}$ \\
\hline Original medium & $3.0 \pm 0.06$ & 9.66 & 10.3 & 0.94 \\
RSM & $58.62 \pm 0.35$ & 120.08 & 10.8 & 11.12 \\
\hline
\end{tabular}

TABLE 8: Yield of $\omega-3 / \omega-6$ fatty acids produced in MSM and optimized medium.

\begin{tabular}{|c|c|c|c|c|c|c|c|c|c|c|c|}
\hline \multicolumn{12}{|c|}{ Fatty acids } \\
\hline & \multicolumn{6}{|c|}{$\omega-6$} & \multicolumn{5}{|c|}{$\omega-3$} \\
\hline & 18:2 (trans) & $18: 2$ (cis) & $18: 3$ & $20: 2$ & $20: 3$ & $20: 4$ & $22: 2$ & $18: 3$ & $20: 3$ & $20: 5$ & $22: 6$ \\
\hline & \multicolumn{11}{|c|}{ MSM } \\
\hline $\begin{array}{l}\text { PUFAs (\% of } \\
\text { total fatty acids) }\end{array}$ & $0.85 \pm 0.42$ & $0.56 \pm 0.35$ & 0.0 & 0.0 & $1.06 \pm 0.55$ & $0.53 \pm 0.09$ & 0.0 & 0.0 & 0.0 & 0.0 & 0.0 \\
\hline $\begin{array}{l}\text { PUFAs } \\
\text { produced } \\
(\mathrm{mg} / \mathrm{L})\end{array}$ & 0.67 & 1.14 & 0.0 & 0.0 & 4.30 & 3.55 & 0.0 & 0.0 & 0.0 & 0.0 & 0.0 \\
\hline
\end{tabular}

$(\mathrm{mg} / \mathrm{L})$

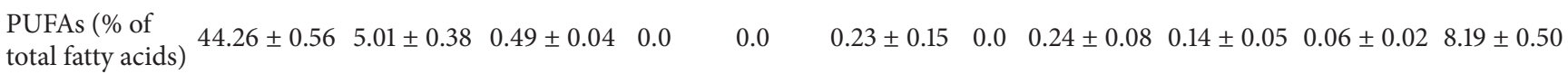

Optimized medium

PUFAs

$\begin{array}{llllllllllll}\text { produced } & 84 & 20.36 & 2.60 & 0.0 & 0.0 & 0.75 & 0.0 & 0.77 & 0.22 & 0.1 & 11.28\end{array}$

$(\mathrm{mg} / \mathrm{L})$

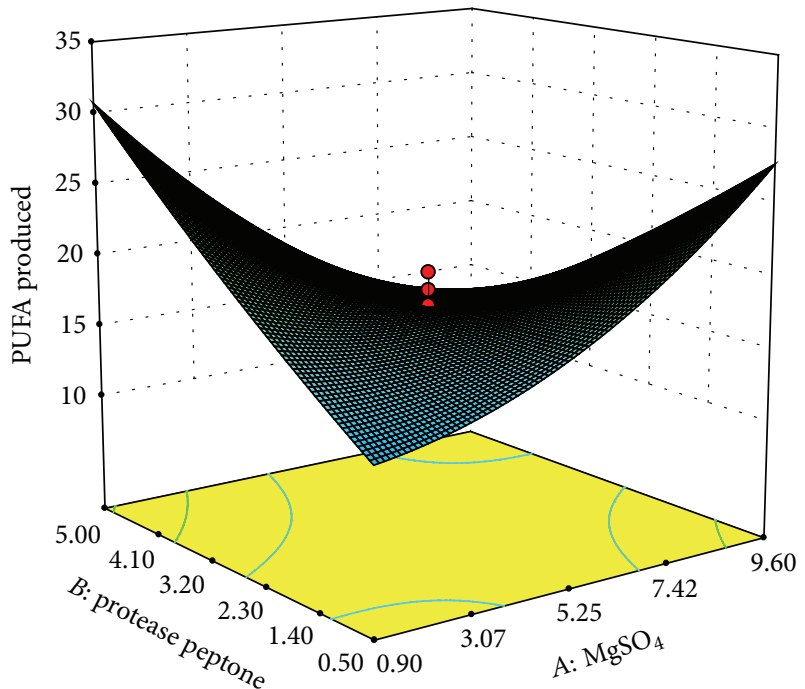

FIGURE 1: Response surface plot of PUFAs produced (\% of total fatty acids) as a function of $\mathrm{MgSO}_{4}(\mathrm{~g} / \mathrm{L})$ and protease peptone $(\mathrm{g} / \mathrm{L})$.

Our results indicated that variables $A$ and $C$ had not only quadratic $\left(A^{2}: P<0.0247 ; C^{2}: P<0.001\right)$ but also interactive effect on PUFA production (Table 6). On the other hand variables $B$ and $D$ were found to have interactive effects only. Amongst the interactive effects, interaction between $A B, A D$, and $B D(P<0.0001)$ was found to be the most significant followed by $A C(P<0.0021)$ and $B C(P<0.0321)$. The optimal values of the variables were determined by constructing three-dimensional plots. The shapes of the plots are suggestive of the significance of the interaction between

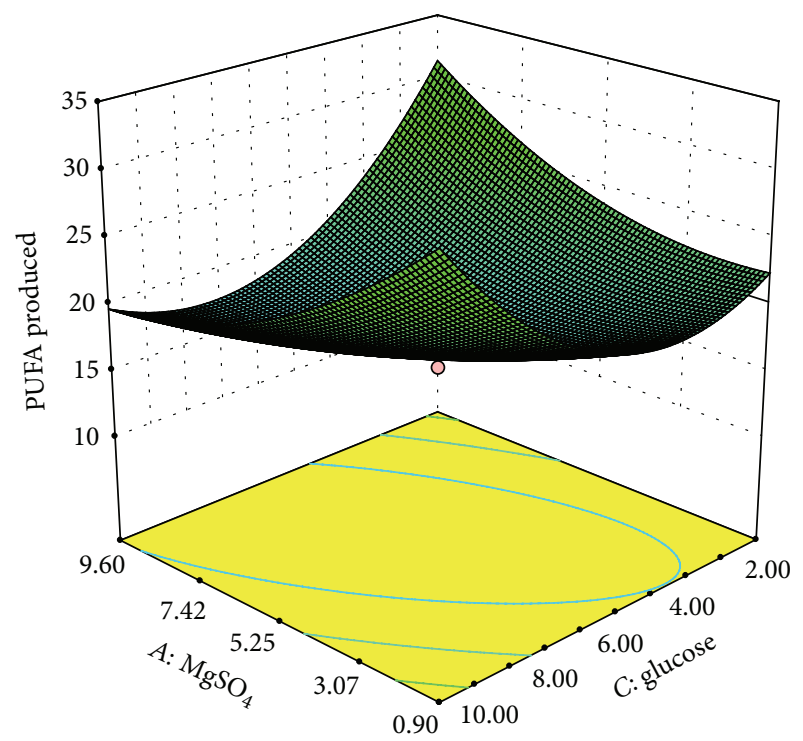

FIGURE 2: Response surface plot of PUFAs produced (\% of total fatty acids) as a function of $\mathrm{MgSO}_{4}(\mathrm{~g} / \mathrm{L})$ and glucose $(\mathrm{g} / \mathrm{L})$.

variables with respect to the response obtained. Elliptical plots indicate a significant interaction whereas circular plots indicate that the interaction between the variables is not a considerable contributor to the response obtained [32]. Here, $\%$ PUFAs obtained were plotted as function of significant interactive variables. The interactive effects of $\mathrm{MgSO}_{4}(A)$ with protease peptone $(B)$, glucose $(C)$, and temperature (D) on PUFA production are demonstrated in Figures 1, 2 , and 3 , respectively. The plots clearly indicate that lower 


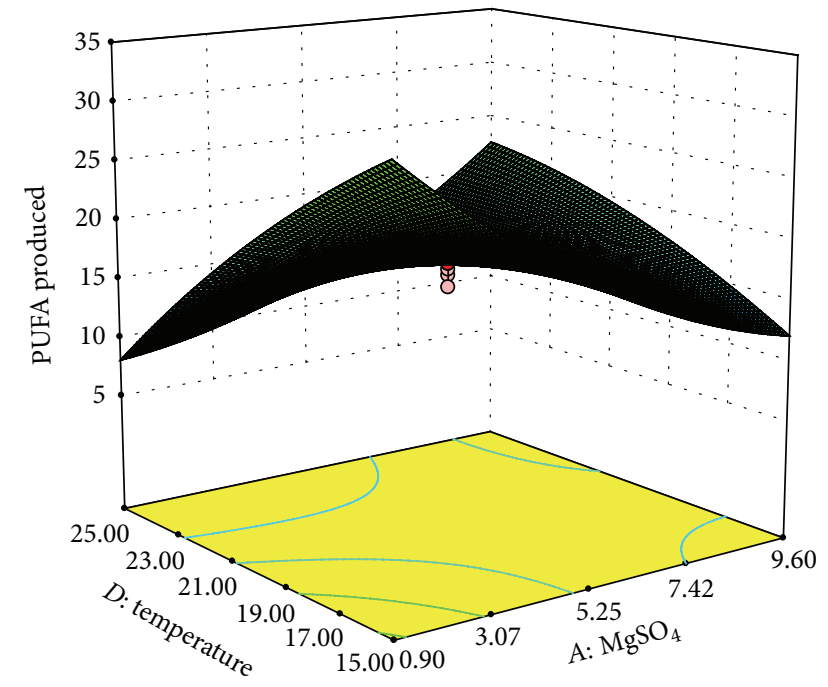

FIGURE 3: Response surface plot of PUFAs produced (\% of total fatty acids) as a function of $\mathrm{MgSO}_{4}(\mathrm{~g} / \mathrm{L})$ and temperature $\left({ }^{\circ} \mathrm{C}\right)$.

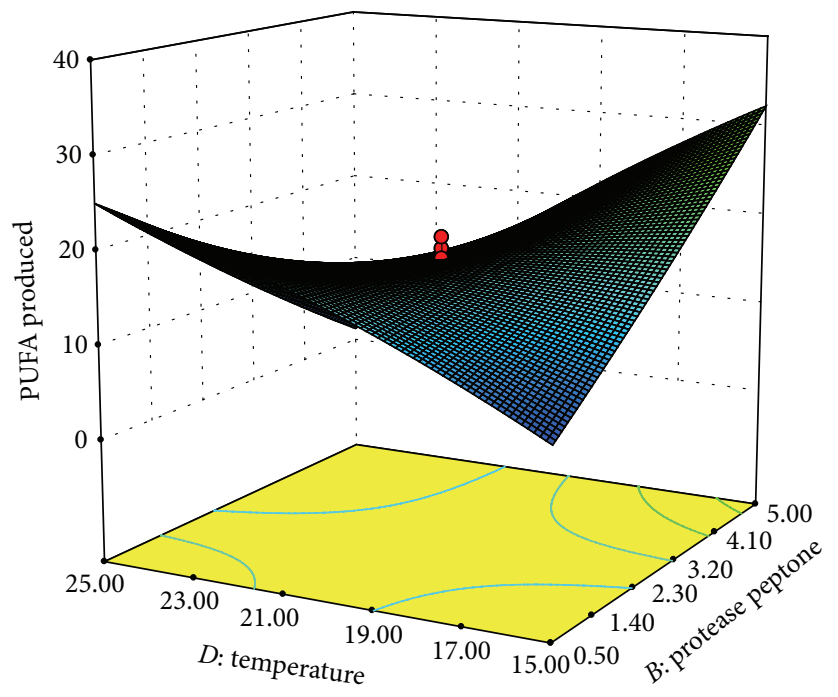

FIGURE 4: Response surface plot of PUFAs produced (\% of total fatty acids) as a function of protease peptone $(\mathrm{g} / \mathrm{L})$ and temperature $\left({ }^{\circ} \mathrm{C}\right)$.

concentrations of $\mathrm{MgSO}_{4}$ are beneficial for PUFA production from Kocuria sp. BRI 35 with maximum production at $0.9 \mathrm{~g} / \mathrm{L}$ $\mathrm{MgSO}_{4}$. Kang et al. [33] have reported maximum overall PUFA production (67.10\%) in medium without $\mathrm{MgSO}_{4}$ from Thraustochytrium aureum ATCC 34304. However, the same bacterium produces DHA optimally at $4.5 \mathrm{~g} / \mathrm{L}$ of $\mathrm{MgSO}_{4}$ [34]. Thus, $\mathrm{MgSO}_{4}$ plays a critical role in overall PUFA production as well as synthesis of individual fatty acids. This may be attributed to its function as a cofactor for enzymes involved in fatty acid synthesis. Hence its addition at proper concentration may increase the efficiency of the enzymes involved in fatty acid synthesis [35].

The interactive effects of temperature $(D)$ with $\mathrm{MgSO}_{4}$ $(A)$ and protease peptone $(B)$ are shown in Figures 3 and 4 , respectively. As depicted in the plots maximum PUFA

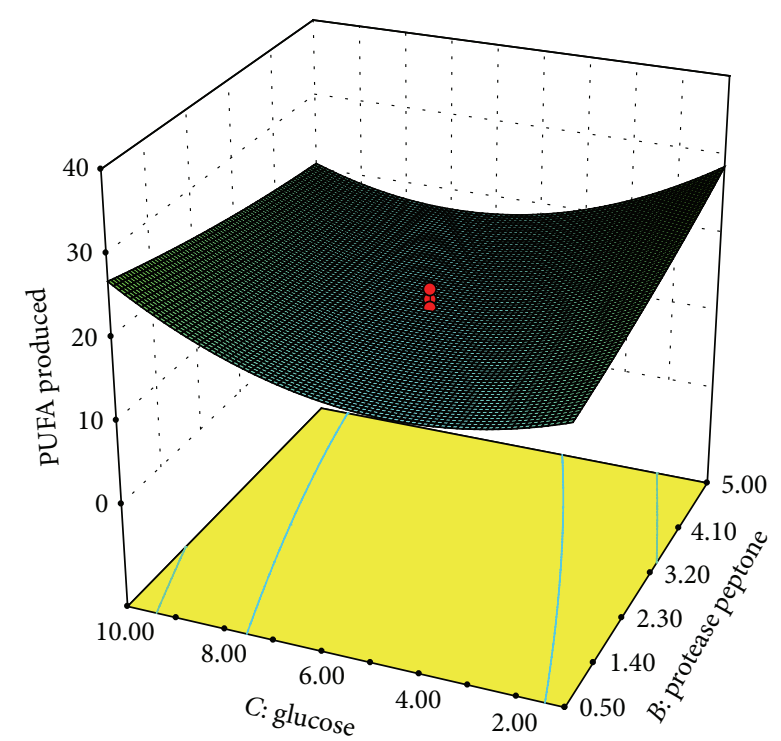

FIgURE 5: Response surface plot of PUFAs produced (\% of total fatty acids) as a function of protease peptone $(\mathrm{g} / \mathrm{L})$ and glucose $(\mathrm{g} / \mathrm{L})$.

production is observed at lower temperature of around $15^{\circ} \mathrm{C}$. The amount of PUFA produced was found to decrease considerably with increase in temperature. Similarly, Nichols et al. [36] have reported maximum EPA (12.2\%) production at $15^{\circ} \mathrm{C}$ from a psychrophilic bacterium isolated from the Antarctic sea. Optimum temperature of $10^{\circ} \mathrm{C}$ was observed by Chodok et al. [2] for overall PUFA production from Physcomitrella patens.

Figure 5 shows the interactive effect of protease peptone $(B)$ and glucose $(C)$ on PUFA synthesis from BRI 35. The isolate produced PUFAs optimally in presence of protease peptone and glucose at $5 \mathrm{~g} / \mathrm{L}$ and $10 \mathrm{~g} / \mathrm{L}$ concentration, respectively. Similarly, Jang et al. [28] have reported optimum $\mathrm{C}: \mathrm{N}$ ratio of $2: 1$ for PUFA production from Mortierella alpina. However authors have used starch as carbon source and $\mathrm{KNO}_{3}$ and yeast extract as nitrogen sources. $\mathrm{C}: \mathrm{N}$ ratio of 25:7 was found to be optimum for production of ARA from Mortierella alpina CBS 754.68 [37]. Higher C: $\mathrm{N}$ ratio $(5: 1)$ for DHA production had been reported by Wu et al. from Schizochytrium sp. S31 [38].

Thus, analysis of RSM plots indicated that maximum PUFAs are obtained from Kocuria sp. BRI 35 under the following fermentation conditions: $\mathrm{MgSO}_{4} \quad 0.94 \mathrm{~g} / \mathrm{L}$; protease peptone $5 \mathrm{~g} / \mathrm{L}$; glucose $10 \mathrm{~g} / \mathrm{L}$; temperature $15^{\circ} \mathrm{C}$. The optimization strategies resulted in significant increase in the amount of PUFAs produced. In original medium PUFAs represented only $3 \%$ of total fatty acids produced. This corresponded to $0.94 \mathrm{mg} / \mathrm{g}$ of biomass. In the optimized medium more than $50 \%$ of fatty acids produced were PUFAs which accounted for $11.12 \mathrm{mg} / \mathrm{g}$ of biomass. Thus, the amount of PUFA's increased from $9.66 \mathrm{mg} / \mathrm{L}$ to $120.08 \mathrm{mg} / \mathrm{L}$ (Table 7). Kocuria sp. BRI 35 exhibited the ability to produce higher amounts of PUFAs in optimized medium without significant increase in the overall lipid content. Earlier Chodok et al. have reported maximum PUFA production of $75.11 \mathrm{mg} / \mathrm{L}$ by 
Physcomitrella patens in medium optimized using PlackettBurman design [2]. Use of sugarcane molasses for PUFA production has been documented by $\mathrm{Li}$ et al. They have reported PUFA production of $5.74 \mathrm{~g} / \mathrm{L}$ from Mucor recurvus under optimized conditions [39]. Presence of increased amounts of PUFAs from Kocuria sp. BRI 35 (this work) in optimized medium is a unique finding since saturated and monounsaturated fatty acids have been mainly reported from the genus Kocuria [40, 41].

Table 8 demonstrates \% increase and quantity $(\mathrm{mg} / \mathrm{L})$ of individual PUFAs produced from BRI 35 following optimization. The amount of $\omega-6$ fatty acids increased from $9.66 \mathrm{mg} / \mathrm{L}$ (3\% of total fatty acids) to $120.08 \mathrm{mg} / \mathrm{L}(50.23 \%$ of total fatty acids). Specifically, yield of linoleic acid increased from $1.14 \mathrm{mg} / \mathrm{L}$ to $20.36 \mathrm{mg} / \mathrm{L}$ under optimized conditions. Along with $\omega-6$ fatty acids, our isolate exhibited the ability to produce $\omega-3$ fatty acids particularly DHA $(11.28 \mathrm{mg} / \mathrm{L})$ under optimal conditions. Similarly, Morita et al. have reported maximum DHA production of $13.4 \mathrm{mg} / \mathrm{L}$ from Moritella sp. [42]. Along with DHA and LA Kocuria sp. BRI 35 also produced several beneficial $\omega-6$ (ARA, GLA) and $\omega-3$ (EPA, ALA) PUFAs (Table 8).

\section{Conclusion}

Optimization of culture conditions for production of PUFAs from Kocuria sp. BRI 35 was accomplished using PlackettBurman design and response surface methodology. $\mathrm{MgSO}_{4}$, protease peptone, glucose, and temperature were found to be the most significant parameters. Under optimized conditions, BRI 35 produced nutritionally important PUFAs like EPA, DHA, ARA, LA, GLA, and ALA. Thus BRI 35 exhibits the potential for commercial production of PUFAs.

\section{Conflict of Interests}

The authors declare that there is no conflict of interests regarding the publication of this paper.

\section{Acknowledgments}

Financial support from the Department of Science and Technology (DST), Government of India, is gratefully acknowledged. The authors are also thankful to Dr. N. N. Nawani (Dr. D. Y. Patil Biotechnology and Bioinformatics Institute, Pune, India) for useful discussions.

\section{References}

[1] V. V. Jadhav, A. Yadav, Y. S. Shouche, and R. K. Bhadekar, "Isolation and cellular fatty acid composition of psychrotrophic Halomonas strains from Antarctic sea water," Songklanakarin Journal of Science and Technology, vol. 35, no. 3, pp. 287-292, 2013.

[2] P. Chodok, A. Kanjana-Opas, and S. Kaewsuwan, "The plackettburman design for evaluating the production of polyunsaturated fatty acids by Physcomitrella patens," Journal of the American Oil Chemists' Society, vol. 87, no. 5, pp. 521-529, 2010.
[3] J. P. Schuchardt, M. Huss, M. Stauss-Grabo, and A. Hahn, "Significance of long-chain polyunsaturated fatty acids (PUFAs) for the development and behaviour of children," European Journal of Pediatrics, vol. 169, no. 2, pp. 149-164, 2010.

[4] K.-P. Su, "Mind-body interface: the role of n-3 fatty acids in psychoneuroimmunology, somatic presentation, and medical illness comorbidity of depression," Asia Pacific Journal of Clinical Nutrition, vol. 17, no. 1, pp. 151-157, 2008.

[5] P. C. Calder, "Omega-3 polyunsaturated fatty acids and inflammatory processes: nutrition or pharmacology?" British Journal of Clinical Pharmacology, vol. 75, no. 3, pp. 645-662, 2013.

[6] S. Maqsood, S. Benjakul, and A. Kamal-Eldin, "Extraction, processing, and stabilization of health-promoting fish oils," Recent Patents on Food, Nutrition, and Agriculture, vol. 4, no. 2, pp. 141-147, 2012.

[7] G. M. Turchini, D. S. Francis, S. P. S. D. Senadheera, T. Thanuthong, and S. S. de Silva, "Fish oil replacement with different vegetable oils in Murray cod: evidence of an "omega3 sparing effect" by other dietary fatty acids," Aquaculture, vol. 315, no. 3-4, pp. 250-259, 2011.

[8] L. Sijtsma and M. E. de Swaaf, "Biotechnological production and applications of the $\omega-3$ polyunsaturated fatty acid docosahexaenoic acid," Applied Microbiology and Biotechnology, vol. 64, no. 2, pp. 146-153, 2004.

[9] V. V. Jadhav, M. M. Jamle, P. D. Pawar, M. N. Devare, and R. K. Bhadekar, "Fatty acid profiles of PUFA producing Antarctic bacteria: correlation with RAPD analysis," Annals of Microbiology, vol. 60, no. 4, pp. 693-699, 2010.

[10] A. Jacobs, A. Botha, and W. H. van Zyl, "The production of eicosapentaenoic acid by representatives of the genus Mortierella grown on brewers' spent grain," Biologia, vol. 64, no. 5, pp. 871-876, 2009.

[11] S. K. Athalye, R. A. Garcia, and Z. Wen, "Use of biodieselderived crude glycerol for producing eicosapentaenoic acid (EPA) by the fungus Pythium irregulare," Journal of Agricultural and Food Chemistry, vol. 57, no. 7, pp. 2739-2744, 2009.

[12] C. Shene, A. Leyton, M. Rubilar, M. Pinelo, F. Acevedo, and E. Morales, "Production of lipids and docosahexasaenoic acid (DHA) by a native Thraustochytrium strain," European Journal of Lipid Science and Technology, vol. 115, no. 8, pp. 890-900, 2013.

[13] T. Klempova, E. Basil, A. Kubatova, and M. Certik, "Biosynthesis of gamma-linolenic acid and beta-carotene by Zygomycetes fungi," Biotechnology Journal, vol. 8, no. 7, pp. 794-800, 2013.

[14] E. G. Dedyukhina, T. I. Chistyakova, S. V. Kamzolova, M. V. Vinter, and M. B. Vainshtein, "Arachidonic acid synthesis by glycerol-grownMortierella alpine," European Journal of Lipid Science and Technology, vol. 114, no. 7, pp. 833-841, 2012.

[15] K. Hirota, Y. Nodasaka, Y. Orikasa, H. Okuyama, and I. Yumoto, "Shewanella pneumatophori sp. nov., an eicosapentaenoic acidproducing marine bacterium isolated from the intestines of Pacific mackerel (Pneumatophorus japonicus)," International Journal of Systematic and Evolutionary Microbiology, vol. 55, no. 6, pp. 2355-2359, 2005.

[16] S. Saelao, A. Kanjana-Opas, and S. Kaewsuwan, "Optimization of biomass and arachidonic acid production by Aureispira maritima using response surface methodology," Journal of the American Oil Chemists' Society, vol. 88, no. 5, pp. 619-629, 2011.

[17] E. E. Allen and D. H. Bartlett, "Structure and regulation of the omega-3 polyunsaturated fatty acid synthase genes from the deep-sea bacterium Photobacterium profundum strain SS9," Microbiology, vol. 148, no. 6, pp. 1903-1913, 2002. 
[18] D. S. Nichols, P. D. Nichols, and T. A. McMeekin, "Polyunsaturated fatty acids in Antarctic bacteria," Antarctic Science, vol. 5, no. 2, pp. 149-160, 1993.

[19] L. Zhou, Y. Lu, M. Zhou, and X. Zhao, "Enhanced production of docosahexaenoic acid using Schizochytrium sp. by optimization of medium components," Journal of Chemical Engineering of Japan, vol. 40, no. 12, pp. 1093-1100, 2007.

[20] A. A. Elrazak, A. C. Ward, and J. Glassey, "Response surface methodology for optimizing the culture conditions for eicosapentaenoic acid production by marine bacteria," Journal of Industrial Microbiology \& Biotechnology, vol. 40, no. 5, pp. 477487, 2013.

[21] T. A. Wani, A. Ahmad, S. Zargar, N. Y. Khalil, and I. A. Darwish, "Use of response surface methodology for development of new microwell-based spectrophotometric method for determination of atrovastatin calcium in tablets," Chemistry Central Journal, vol. 6, pp. 134-142, 2012.

[22] E. Bligh and W. Dyer, "A rapid method of total lipid extraction and purification," Canadian Journal of Biochemistry and Physiology, vol. 37, no. 8, pp. 911-917, 1959.

[23] V. V. Jadhav, D. S. Salunkhe, and R. K. Bhadekar, "Effect of alterations in conventional medium on lipid accumulation and fatty acid content in oleaginous yeast," International Journal of Pharmacy and Biological Sciences B, vol. 3, no. 4, pp. 757-769, 2012.

[24] K. Ichihara and Y. Fukubayashi, "Preparation of fatty acid methyl esters for gas-liquid chromatography," Journal of Lipid Research, vol. 51, no. 3, pp. 635-640, 2010.

[25] S. S. Pote, Y. Chaudhary, S. Upadhayay et al., Studies on biotechnological potential of the marine bacterial isolates (communicated), 2014.

[26] S.-H. Yang, J.-H. Lee, J.-S. Ryu, C. Kato, and S.-J. Kim, "Shewanella donghaensis sp. nov., a psychrophilic, piezosensitive bacterium producing high levels of polyunsaturated fatty acid, isolated from deep-sea sediments," International Journal of Systematic and Evolutionary Microbiology, vol. 57, no. 2, pp. 208212, 2007.

[27] E. E. Allen, D. Facciotti, and D. H. Bartlett, "Monounsaturated but not polyunsaturated fatty acids are required for growth of the deep-sea bacterium Photobacterium profundum SS9 at high pressure and low temperature," Applied and Environmental Microbiology, vol. 65, no. 4, pp. 1710-1720, 1999.

[28] H.-D. Jang, Y.-Y. Lin, and S.-S. Yang, "Effect of culture media and conditions on polyunsaturated fatty acids production by Mortierella alpina," Bioresource Technology, vol. 96, no. 15, pp. 1633-1644, 2005.

[29] V. M. Furlan, M. Paulo, I. Batista, N. M. Bandarra, M. L. E. Santo, and C. Prentice, "Effect of the concentration of glucose in the docosahexaenoic acid (DHA) production byThraustochytrium sp., ATCC, 26185," Advance Journal of Food Science and Technology, vol. 4, no. 5, pp. 257-264, 2012.

[30] Y.-X. Wang and Z.-X. Lu, "Optimization of processing parameters for the mycelial growth and extracellular polysaccharide production by Boletus spp. ACCC 50328," Process Biochemistry, vol. 40, no. 3-4, pp. 1043-1051, 2005.

[31] A. F. D. Vasconcelos, A. M. Barbosa, R. F. H. Dekker, I. S. Scarminio, and M. I. Rezende, "Optimization of laccase production by Botryosphaeria sp. in the presence of veratryl alcohol by the response-surface method," Process Biochemistry, vol. 35, no. 10, pp. 1131-1138, 2000.

[32] R. V. Muralidhar, R. R. Chirumamila, R. Marchant, and P. Nigam, "A response surface approach for the comparison of lipase production by Candida cylindracea using two different carbon sources," Biochemical Engineering Journal, vol. 9, no. 1, pp. 17-23, 2001.

[33] D.-H. Kang, E.-J. Jeh, J.-W. Seo, B.-H. Chun, and B.-K. Hur, "Effect of salt concentration on production of polyunsaturated fatty acids in Thraustochytrium aureum ATCC 34304," Korean Journal of Chemical Engineering, vol. 24, no. 4, pp. 651-654, 2007.

[34] K. H. Min, H. H. Lee, P. Anbu, B. P. Chaulagain, and B. K. Hur, "The effects of culture condition on the growth property and docosahexaenoic acid production from Thraustochytrium aureum ATCC, 34304," Korean Journal of Chemical Engineering, vol. 29, no. 9, pp. 1211-1215, 2012.

[35] F. Muhid, W. N. N. W. Nawi, A. J. A. Kader, W. M. W. Yusoff, and A. A. Hamid, "Effects of metal ion concentrations on lipid and gamma linolenic acid production by Cunninghamella sp. 2A1," OnLine Journal of Biological Sciences, vol. 8, no. 3, pp. 62-67, 2008.

[36] D. S. Nichols, J. L. Brown, P. D. Nichols, and T. A. McMeekin, "Production of eicosapentaenoic and arachidonic acids by an Antarctic bacterium: response to growth temperature," FEMS Microbiology Letters, vol. 152, no. 2, pp. 349-354, 1997.

[37] K. Rocky-Salimi, Z. Hamidi-Esfahani, and S. Abbasi, "Statistical optimization of arachidonic acid production by Mortierella alpina CBS 754.68 in submerged fermentation," Iranian Journal of Biotechnology, vol. 9, no. 2, pp. 87-93, 2011.

[38] S.-T. Wu, S.-T. Yu, and L.-P. Lin, "Effect of culture conditions on docosahexaenoic acid production by Schizochytrium sp. S31," Process Biochemistry, vol. 40, no. 9, pp. 3103-3108, 2005.

[39] N. Li, Z.-N. Deng, Y.-L. Qin, C.-L. Chen, and Z.-Q. Liang, "Production of polyunsaturated fatty acids by Mucor recurvus sp. with sugarcane molasses as the carbon source," Food Technology and Biotechnology, vol. 46, no. 1, pp. 73-79, 2008.

[40] G. S. N. Reddy, J. S. S. Prakash, V. Prabahar, G. I. Matsumoto, E. Stackebrandt, and S. Shivaji, "Kocuria polaris sp. nov., an orange-pigmented psychrophilic bacterium isolated from an Antarctic cyanobacterial mat sample," International Journal of Systematic and Evolutionary Microbiology, vol. 53, no. 1, pp. 183187,2003

[41] S. B. Kim, O. I. Nedashkovskaya, V. V. Mikhailov et al., "Kocuria marina sp. nov., a novel actinobacterium isolated from marine sediment," International Journal of Systematic and Evolutionary Microbiology, vol. 54, no. 5, pp. 1617-1620, 2004.

[42] N. Morita, T. Nishida, M. Tanaka, Y. Yano, and H. Okuyama, "Enhancement of polyunsaturated fatty acid production by cerulenin treatment in polyunsaturated fatty acid-producing bacteria," Biotechnology Letters, vol. 27, no. 6, pp. 389-393, 2005. 

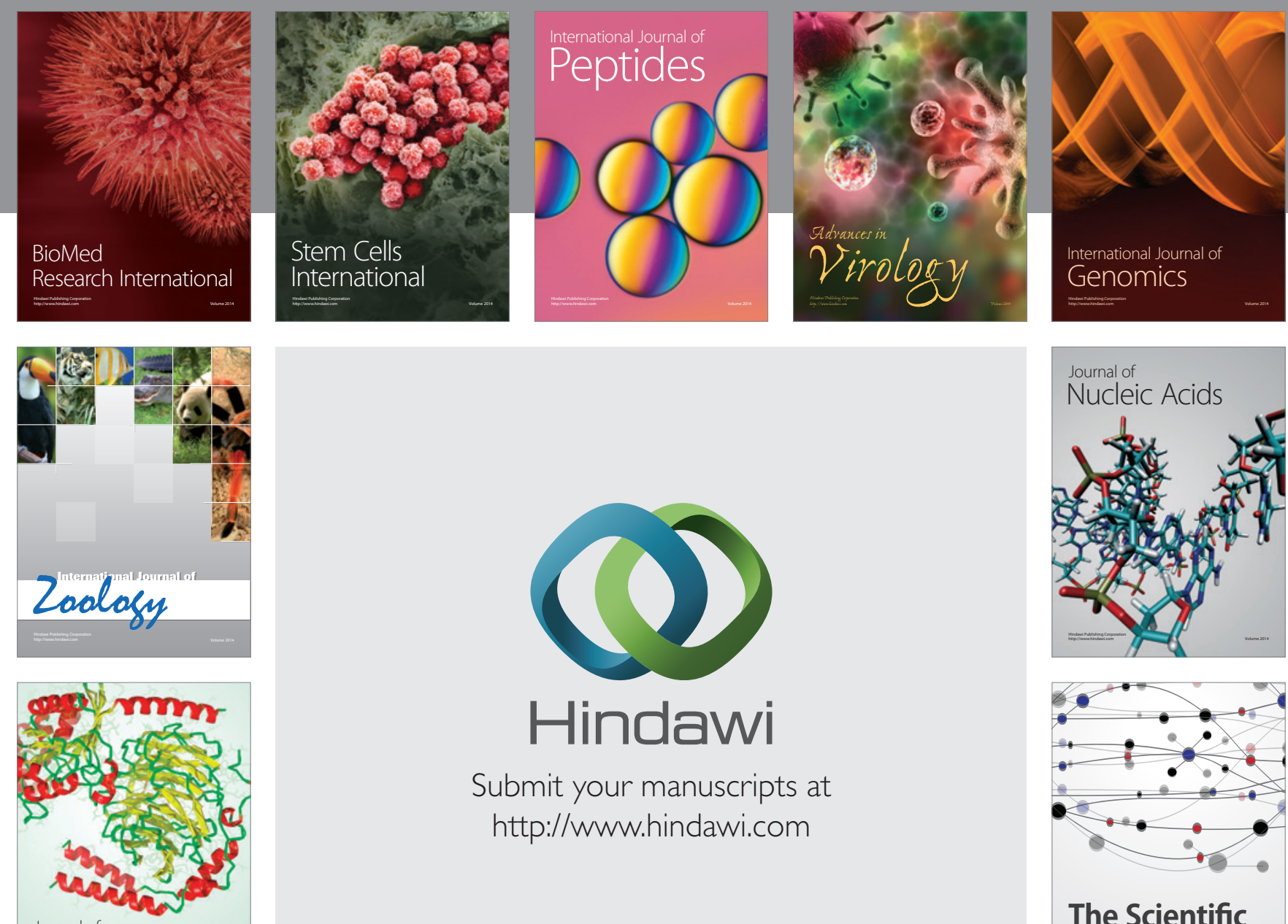

Submit your manuscripts at

http://www.hindawi.com

Journal of
Signal Transduction
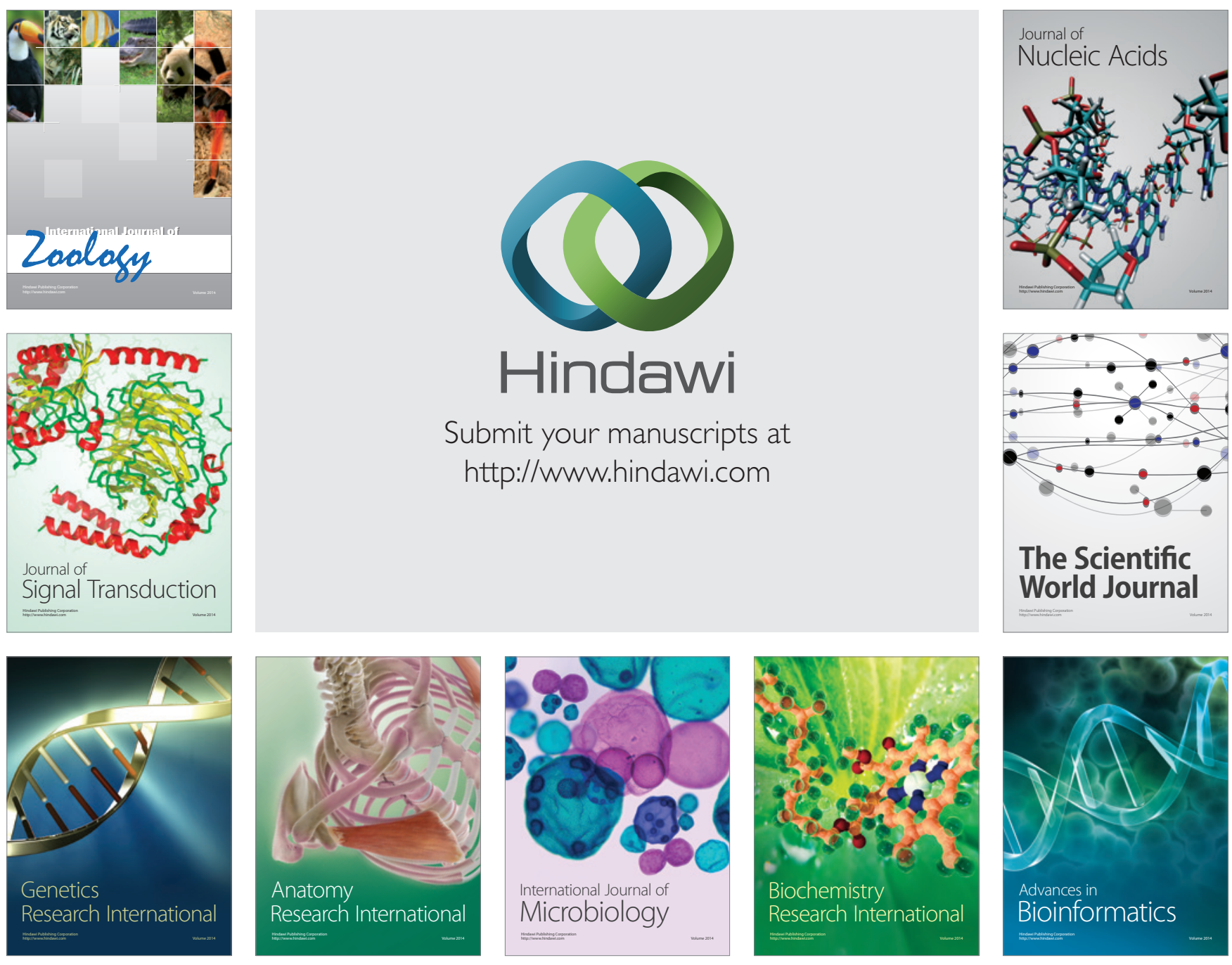

The Scientific World Journal
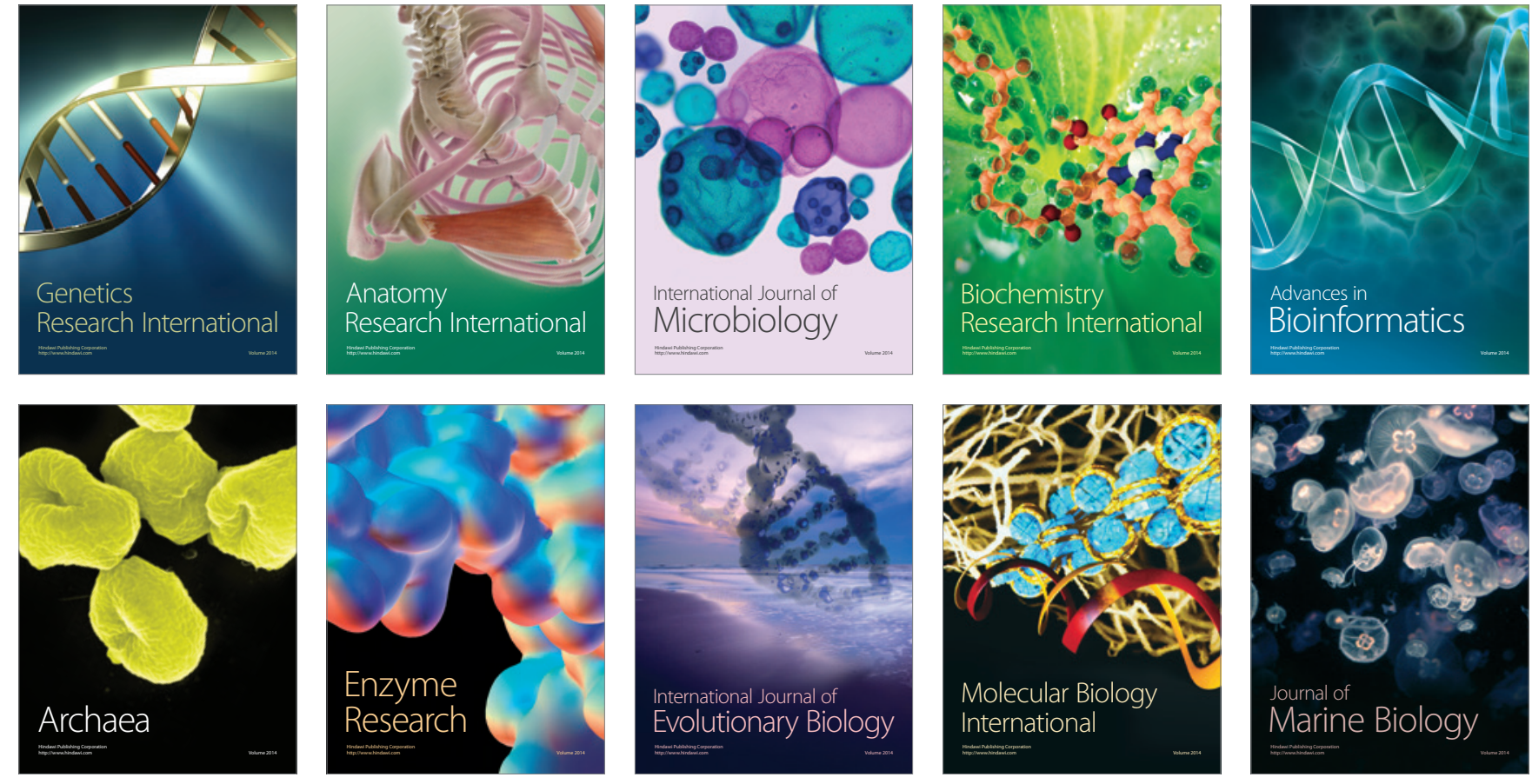